\title{
Tamoxifen represses alcohol-induced transcription of RNA polymerase III-dependent genes in breast cancer cells
}

\author{
Qian Zhong ${ }^{1,2}$, Ganggang Shi ${ }^{3}$, Qingsong Zhang ${ }^{1}$, Lei Lu ${ }^{1}$, Daniel Levy ${ }^{1}$ and Shuping \\ Zhong $^{1,3}$ \\ ${ }^{1}$ Department of Biochemistry and Molecular Biology, Keck School of Medicine, University of Southern California, Los Angeles, \\ CA, USA \\ ${ }^{2}$ State Key Laboratory of Oncology in South China, Sun Yat-sen University Cancer Center, China \\ ${ }^{3}$ Shantou University Medical College, Shantou, Guangdong, China \\ Correspondence to: Shuping Zhong, email: szhong@usc.edu \\ Keywords: Tamoxifen, Alcohol, Estrogen receptor, C-Jun, Brf1, Pol III genes, Breast cancer \\ Received: August 23, $2014 \quad$ Accepted: November 04, $2014 \quad$ Published: November 04, 2014
}

This is an open-access article distributed under the terms of the Creative Commons Attribution License, which permits unrestricted use, distribution, and reproduction in any medium, provided the original author and source are credited.

\section{ABSTRACT}

Alcohol consumption in women has been associated with an increased risk of breast cancer, particular in estrogen receptor positive $(E R+)$ cases. Deregulation of RNA polymerase III-dependent (PoI III) transcription enhances cellular tRNAs and 5S rRNA production, leading to an increase in translational capacity to promote cell transformation and tumor formation. Our recent studies demonstrated that alcohol induces Brf1 expression and Pol III gene transcription via ER. Here, we report that Tamoxifen (Tam) inhibits the induction of Brf1 and Pol III genes in ER+ breast cancer cells. Further analysis indicates that alcohol increases c-Jun expression to upregulate the transcription of Brf1 and Pol III genes, whereas Tam reduces cJun expression to repress the transcription of Brf1. Repression of $\mathrm{c}-J$ un decreases cellular levels of ERa and Brf1. Alcohol-dependent increased occupancy of Brf1 in Pol III gene promoters is reduced by Tam. The repression of Brf1 and Pol III genes by Tam reduces alcoholinduced cell proliferation and colony formation. Together, these results indicate that Tam inhibits alcohol-induced Brf1 expression through c-Jun and ERa to downregulate Pol III gene transcription. Our studies uncover a new mechanism of Tam-treated ER+ breast cancer, by which Tam inhibits tumor growth through repressing Pol III gene transcription.

\section{INTRODUCTION}

Tamoxifen (Tam) is an antagonist of the estrogen receptor (ER) in breast tissue, which competitively binds to ER, producing a nuclear complex that decreases DNA synthesis and inhibits estrogen effects. Tam is currently used for the treatment of both early and advanced ER+ breast cancer in women [1]. Tam causes cells to remain in the $\mathrm{G}_{0}$ and $\mathrm{G}_{1}$ phases of the cell cycle to repress cell proliferation. Studies have indicated that Tam takes part in the regulation of gene transcription, such as c-Jun and c-Fos [2]. However, it is not clear whether Tam affects transcription of RNA polymerase III-dependent genes (Pol III genes), a variety of untranslated RNAs, including tRNAs, 5S rRNAs, which control the translational and growth capacity of cells [3-4]. Deregulation of Pol
III genes is tightly linked to tumor development. Brf1 (TFIIB-related factor 1) specifically regulates Pol III gene transcription. Brf1 and products of Pol III genes are elevated in both transformed and tumor cells suggesting that they play a crucial role in tumorigenesis. Oncogenic proteins stimulate Pol III gene transcription [4-7]; whereas tumor suppressors repress this transcription [4-8]. Consistent with this idea, enhanced Pol III gene transcription is required for oncogenic transformation $[7$, 9].

Alcohol consumption is consistently associated with increased risk for breast cancer in women [10-12]. This association involves the ER, which is over-expressed in approximately $70-80 \%$ of breast cancer cases [13-14]. Alcohol is known to promote mammary tumorigenesis [15-20]. Our studies indicate that enhancement of Brf1 and 
Pol III gene expression is correlated with tumor formation in alcohol-fed mice [21]. We demonstrated that ethanol caused increase in expression of c-Jun, which upregulates transcription of Brf1 and Pol III genes in liver cells [21]. Alcohol enhances Brfl and Pol III gene expression via the ER pathway in MCF-7 cells [22]. Alcohol elevates $\mathrm{ER} \alpha$ activity and inhibition of ER $\alpha$ reduces Pol III gene transcription [22]. Given that Tam represses AP-1 (c-jun and $c$-fos) activity and AP-1 modulates ER $\alpha$ expression $[2,23]$, it implies that Tam may affect transcription of Pol III genes. Here, our studies demonstrate, for the first time, that Tam inhibits Brfl expression and Pol III gene transcription via the c-Jun and ER $\alpha$ pathway to repress cell proliferation and transformation. These studies enhance our understandings of the mechanism of Tam treatment of $\mathrm{ER}+$ breast cancer cases and provide a potential approach to improve the efficacy of Tam by the co-utilization of potential inhibitors of this pathway to repress Pol III gene transcription.

\section{RESULTS}

\section{Tam represses Pol III gene transcription via the alteration of Brf1}

Our study has demonstrated that alcohol induced RNA Pol III-dependent transcription in vitro and in vivo by using cell culture model and animal model [21]. Recent, we have reported that alcohol increases ER $\alpha$ expression to upregulate transcription of Pol III genes [22]. To investigate whether Tam affects Pol III gene transcription, human breast cells were treated with ethanol and the amounts of precursor tRNA ${ }^{\mathrm{Leu}}$ and $5 \mathrm{~S}$ rRNA transcript were measured by RT-qPCR. The results reveal that ethanol induces the transcription of Pol III genes, both pre-tRNA ${ }^{\text {Leu }}$ (Fig. 1A) and 5S rRNA (Fig. 1B), where the induction of Pol III genes in ER+ breast cancer cells lines (MCF-7 and T47D) is dramatically higher than in ER- breast cell lines, both cancer lines (MDA-MB231, SK-BR-3) and non-tumor lines (MCF-10A, MCF-10C and MCF-12A) (Fig. 1). These results demonstrate that alcohol-increased transcription of Pol III genes is associated with ER $\alpha$ expression. Tam is an antagonist of ER, which has widely been used in treatment of breast cancer. Given that alcohol increased ER $\alpha$ expression and reduction of ER $\alpha$ by its siRNA repressed Pol III gene activity [22], this implies that Tam may affect the Pol III genes. The results show that Tam treatment markedly inhibits the induction of pre-tRNA ${ }^{\text {Leu }}$ (Fig. 2A) or $5 \mathrm{~S}$ rRNA (Fig. 2B) of MCF-7 cells by alcohol, but does not affect TFIIIC $_{63}$, a non-Pol III-dependent gene (S1). This inhibition of Pol III genes by Tam is concentrationdependent and peaks at $12.5 \mu \mathrm{M}$ Tam for 1 hour (h). Thus, this condition was used for the entire study unless stated otherwise. We then assessed the effect of Tam on Pol III genes in other breast cancer cell lines. The results indicate that Tam does not affect transcription of Pol III genes in ER- breast cancer cell lines of MDA-MB231 (Fig. 2C and 2D) and SK-BR-3 (Fig. 2E and 2F). Tam does not significantly affect Pol III gene transcription in MCF-7 cells without alcohol treatment (data not shown). These results support the idea that Tam represses Pol III gene transcription in an ER-dependent manner.

Brfl is a key transcription factor regulating tRNA and 5S rRNA genes. Repressing Brfl decreases Pol III gene transcription [22,24,25]. Therefore, we further determined whether Tam alters Brf1 expression. The results indicate that Tam treatment decreases cellular levels of Brf1 mRNA and protein (Fig. 3A and 3B). To explore how Tam affects Pol III gene transcription, we performed chromatin immunoprecipitation (ChIP) assay. The results indicate that Tam reduces the occupancy of Brfl in the promoters of tRNA ${ }^{\text {Leu }}$ and 5S rRNA (Fig. 3C
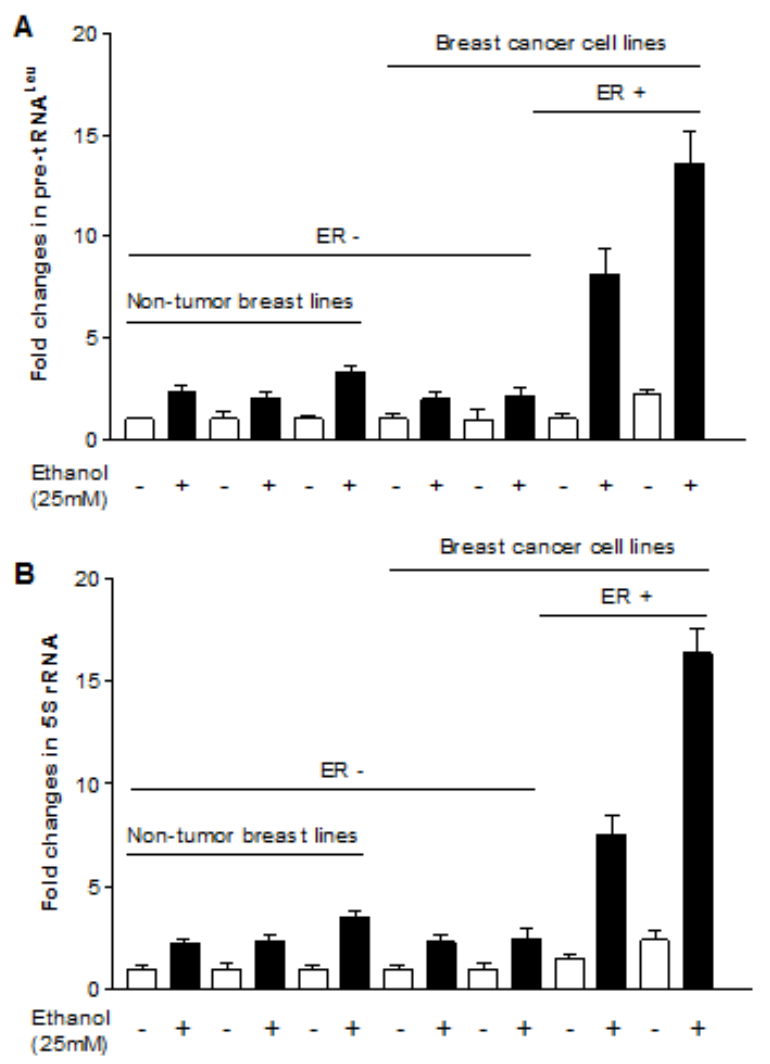

Fig.1: Alcohol induces RNA Pol III-dependent transcription. ER + breast cancer cell lines (MCF-7 and T47D), ER- breast cancer cell lines (MDA-MB231 and SKBR3 ) and ER- non tumor cell lines (MCF-10F, MCF-12A and MCF-10A) were starved in FBS/DMEM-F12 for 3h. Cells were treated with or without $25 \mathrm{mM}$ of ethanol. RNAs were isolated from these cells and RT-qPCR was performed to measure the amounts of pre-tRNA ${ }^{\text {Leu }}(\mathrm{A}), 5 \mathrm{~S}$ rRNA (B). The fold change was calculated by normalizing to the amount of GAPDH mRNA. The bars represent Mean \pm SE of at least three independent determinations. 
and 3E), compared to control of H3 (Fig. 3D and 3F). This indicates that Tam repress Pol III gene transcription through its inhibition of Brfl expression.

\section{Reduction of c-Jun expression affects alcohol- induced Pol III gene transcription}

As alcohol increases the c-Jun expression to elevate Brf1 and Pol III gene transcription in liver cells [21], we examine whether Tam affects the induction of c-Jun caused by alcohol in MCF-7 cells. The results reveal that alcohol increases c-Jun expression in MCF-7 cells, whereas Tam treatment reduces cellular levels of c-Jun

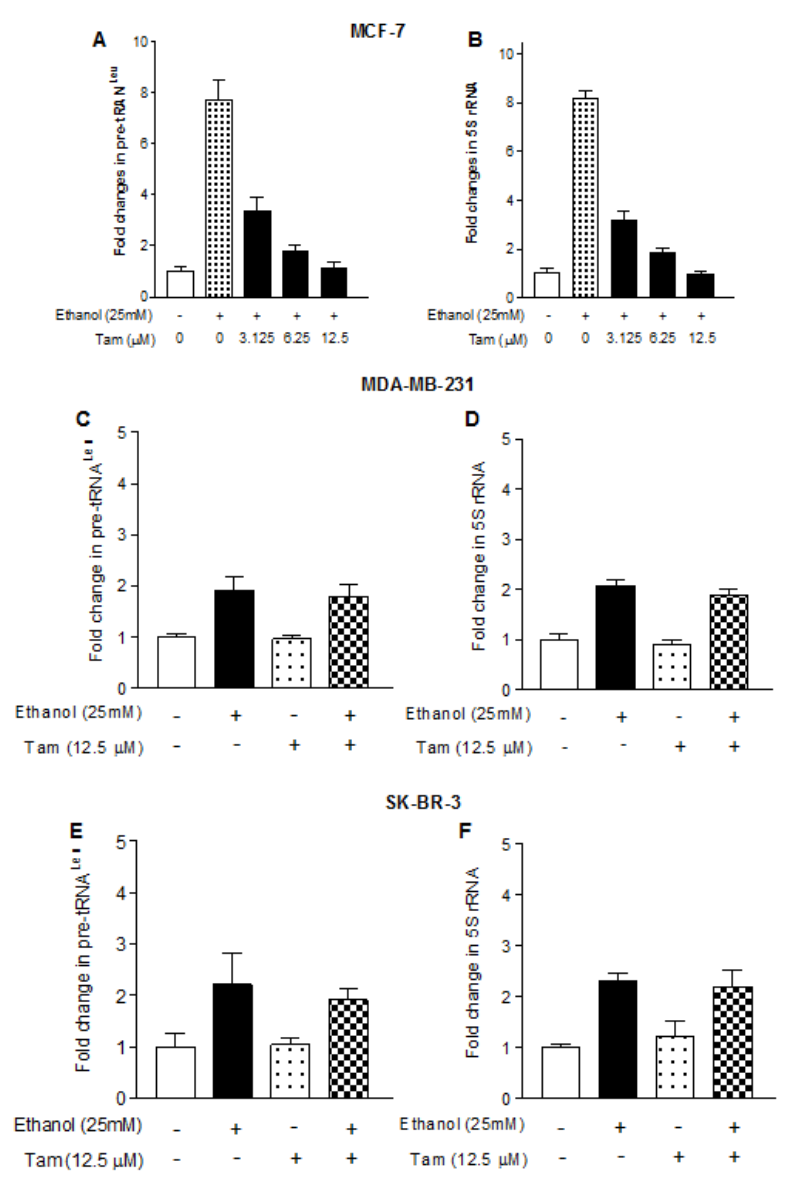

Fig.2: Tam represses RNA Pol III-dependent transcription. (A and $\mathrm{B}$ ): the cells of $\mathrm{ER}+\mathrm{MCF}-7$ breast cancer lines were starved in DMEM-F12 for $3 \mathrm{~h}$. Cells were pretreated with different amounts of Tam for 1 hour, and then treated with $25 \mathrm{mM}$ ethanol for another $1 \mathrm{~h}$ as indicated in Fig. 1. (C-F): the cells of ER- MDA-MB231 (C and D) and SKBR3 (E and F) were pretreated with $12.5 \mu \mathrm{M}$ Tam for $1 \mathrm{~h}$ and then treated with $25 \mathrm{mM}$ ethanol. Total RNAs were extracted from these cells and RT-qPCR was performed to measure the amounts of pre-tRNA ${ }^{\text {Leu }}(\mathrm{A}, \mathrm{C}, \mathrm{E})$ and $5 \mathrm{~S}$ rRNA $(\mathrm{B}, \mathrm{D}, \mathrm{F})$. The fold change was calculated by normalizing to the amount of GAPDH mRNA. The bars represent Mean $\pm \mathrm{SE}$ of at least three independent determinations. protein and mRNA (Fig. 4A and 4C). Therefore, we further analyze how Tam changes Brfl expression. The results indicate that repression of c-Jun by its siRNA decreases cellular levels of c-Jun protein (Fig. 4B) and mRNA (Fig. 4D). Further analysis indicates that repression of c-Jun by its siRNA reduces the levels of proteins and mRNAs of ER $\alpha$ (Fig. 4B and Fig. 4E) and Brf1 (Fig. 4B and 4F). Reduction of c-Jun by its siRNA also decreases alcoholinduced transcription of tRNA ${ }^{\text {Leu }}$ (Fig. 4G) and 5S rRNA (Fig. 4H). Next, we investigated how Tam affects Brfl expression. We performed ChIP assays to determine if Tam affects occupancy of ER $\alpha$ in the Brfl promoter (Fig.5A). The results reveal that ethanol increases the occupancy of ER $\alpha$ in Brfl promoters near its transcription start site

A
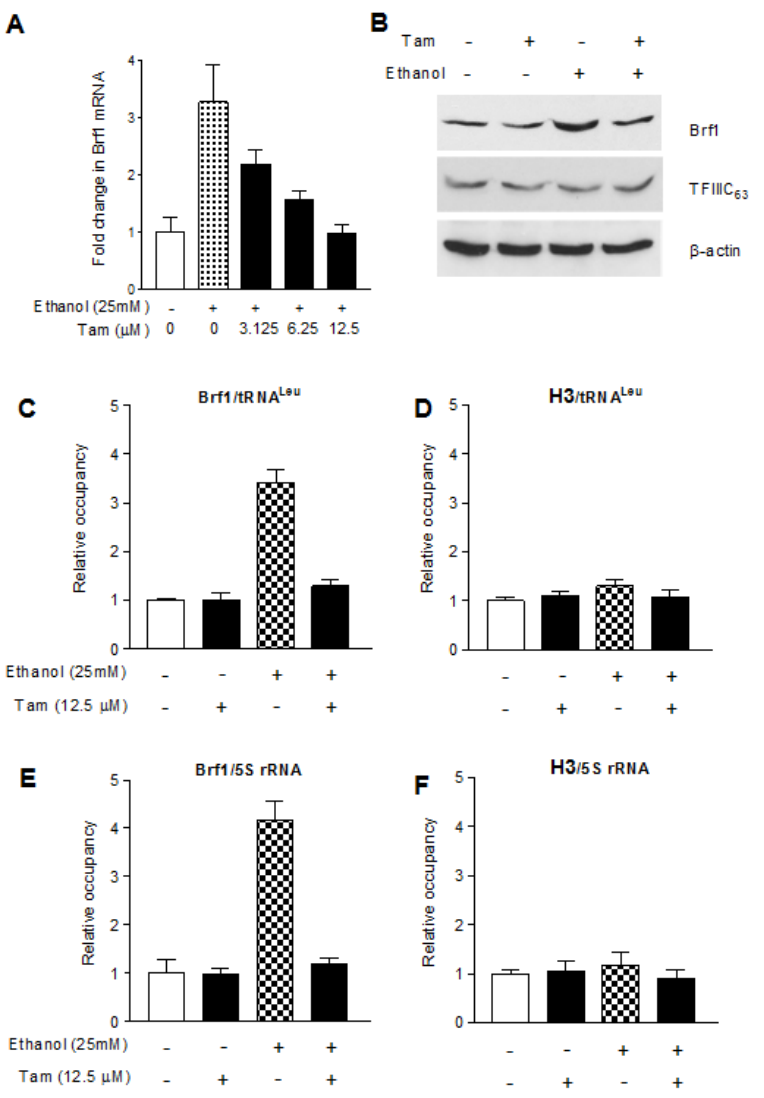

Fig.3: Tam reduces Brf1 expression and lowers the occupancy of Brf1 in the promoters of Pol III genes. (A-B) Tam decreased Brfl expression. MCF-7 cells were starved in DMEM-F12 for $3 \mathrm{~h}$ and treated with Tam as indicated in Fig. 2A. The total RNA and cell lysates from these cells were extracted to determine mRNA and protein of Brfl (A and B) and TFIIIC63 (S1) by RT-qPCT and immunoblot analysis as described previously [22]. (C-F) Tam-lowered Brfl binding to the promoters. MCF-7 cells were treated with Tam as described above. ChIP assays were performed using Brf1 (C and E) and histone H3 (D and F) antibodies and qPCR to quantify the amplified DNA as described previous [22]. The relative occupancy of the proteins was calculated based on the control (no Tam treatment). All values shown are the means $\pm \mathrm{SE}$ of at least three independent chromatin preparations. 
(TSS) in MCF-7 cells (Fig. 5C), but not in upstream of the TSS (Fig. 5B). It suggests that ER $\alpha$ is able to directly regulate Brf1 to modulate Pol III gene transcription [22], whereas Tam treatment inhibits the ability of ER $\alpha$ binding to Brf1 promoter (Fig. 5C). It suggests that Brf1 may be a target of Tam. Furthermore, the repression of c-Jun by its siRNA results in decrease in occupancy of Brfl in the
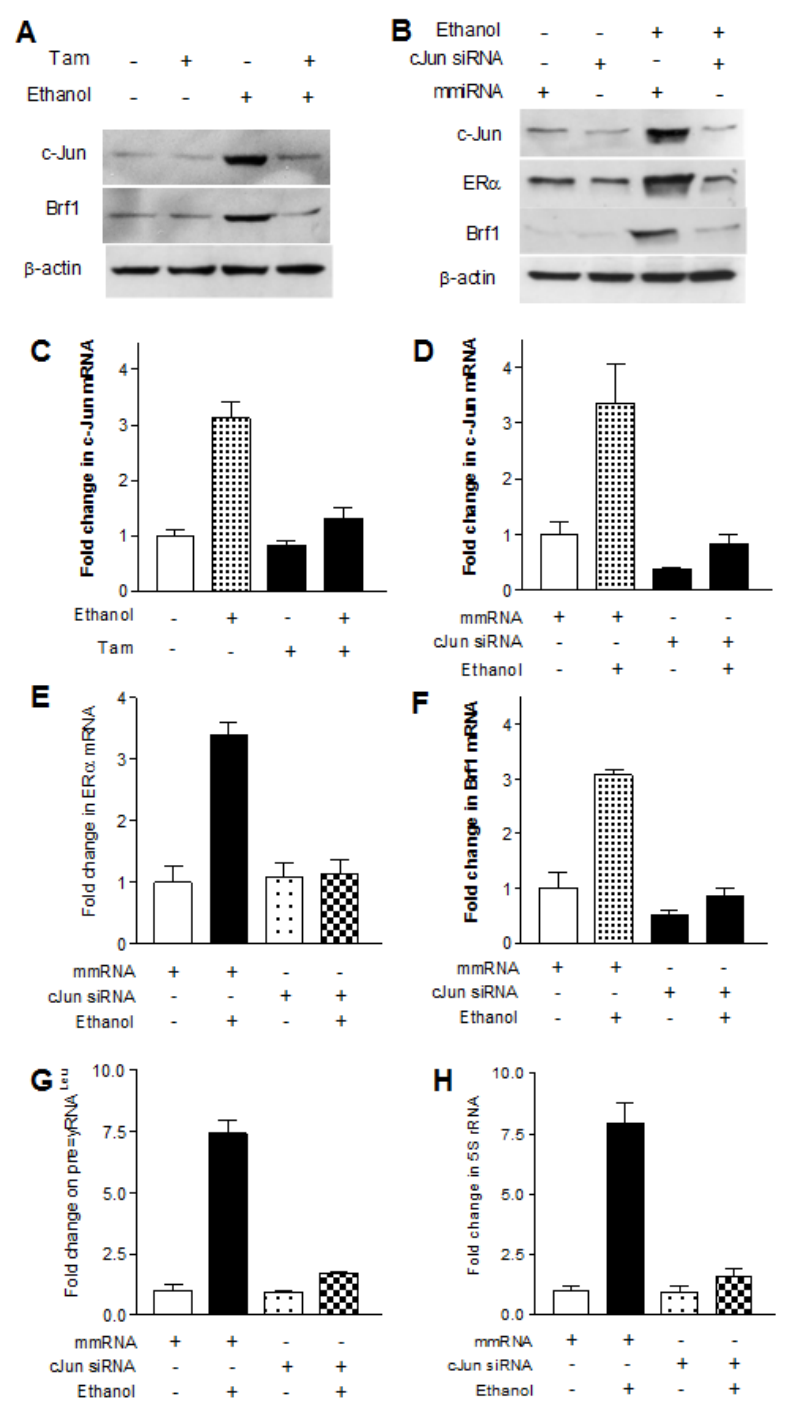

Fig.4: Down-regulating c-Jun decreases expression of Brf1 and Pol III genes. (A and C) Decrease in c-Jun expression MCF-7 cells were treated as described in Fig.2. The cellular levels of c-Jun protein (A) and mRNA (C) were determined. Tam reduces the expression of c-Jun increased by alcohol. (B, D, E and F); c-jun siRNA MCF-7 cells were transfected with mismatch RNA (mmRNA) or c-Jun siRNA for $48 \mathrm{~h}$. The cells were treated as described in A. RT-qPCR and immunoblot analysis was performed to determine cellular levels of c-Jun (B and D), ER $\alpha$ (B and E), and Brf1 (B and F); (G-H) Pol III gene transcription The cells were treated as described above. Total RNAs were extracted from these cells and RT-qPCR was performed to measure the amounts of pre-tRNA ${ }^{\text {Leu }}(\mathrm{G})$ and $5 \mathrm{~S}$ rRNA $(\mathrm{H})$. The fold change was calculated by normalizing to the amount of GAPDH mRNA. The bars represent Mean \pm SE of at least three independent determinations. promoters of tRNA ${ }^{\text {Leu }}$ (Fig. 5D) and 5S rRNA (Fig. 5E), leading to downregulation of Pol III genes $[22,24,25]$. This implies that the alteration of c-Jun by Tam is important for alcohol-increased expression of Brf1 and Pol III genes in $\mathrm{ER}+$ breast cancer cells. Tam decreases the rates of proliferation and
transformation of MCF- 7 cells

Previous studies demonstrated that decreasing expression of Brf1 and Pol III genes was sufficient for repression of cell transformation $[9,22,24]$. Inhibition of Brfl expression reduced anchorage-independent colonies to form and promoted tumor formation in mouse [9]. Our recent studies have further demonstrated that repression of Brfl expression and Pol III gene transcription is able to inhibit alcohol-induced colony formation [22]. To further assess the effect of Tam on alcohol-caused phenotypic alteration, we perform a soft agar assay. The results show that alcohol enhances the rate of colony formation of MCF-7 cells (Fig. 6A), whereas Tam represses the cell anchorage-independent growth in a dose-dependent

A
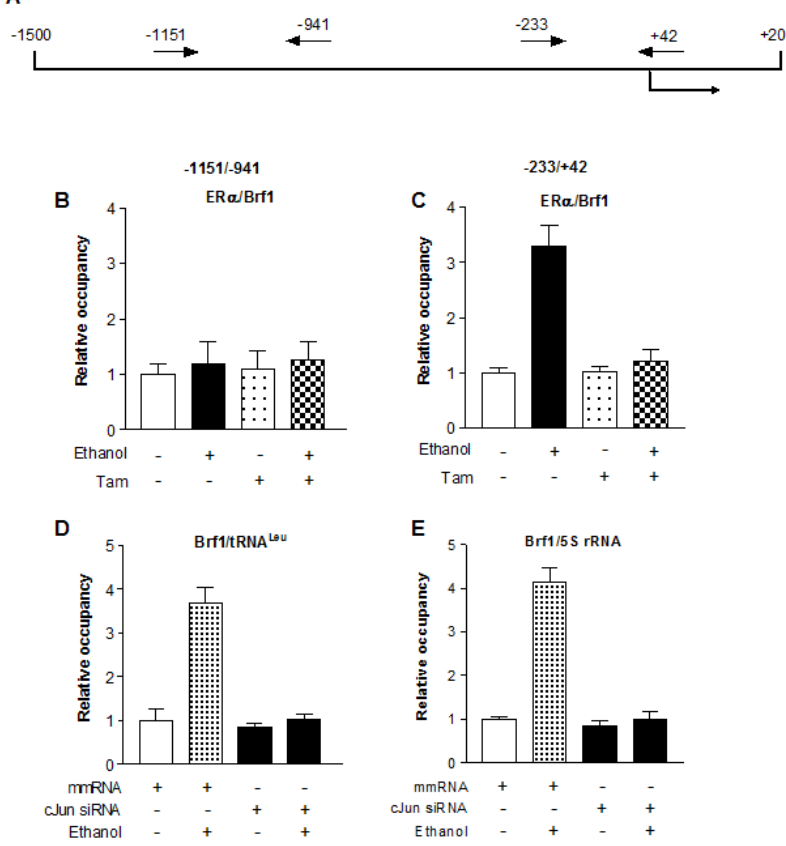

Fig.5: Tam reduces ER $\alpha$ binding to the promoters of Brf1 (A-C) ERa binding to Brf1 promoter. Schematic of the Brfl promoter and primers used for ChIP assays are designated relative to the ER $\alpha$ site (A). MCF-7 cells treated with Tam and alcohol as described above to extract chromatin. ChIP assay were performed with ER $\alpha$ antibody to determine occupancy of ER $\alpha$ in the Brfl promoter; (D-E) Brfl binding to the promoters of Pol III genes The cells were treated as described above. ChIP assay were performed with Brfl antibody and qPCR to quantify the amplified DNA of tRNA ${ }^{\text {Leu }}$ (D) and 5S rRNA (E). The relative occupancy of the proteins was calculated based on the control (no Tam treatment). All values shown are the means $\pm \mathrm{SE}$ of at least three independent experiments. 
manner (Fig. 6A and 6B). The results of MCF-7 cell growth curve indicate that Tam lowers the rate of alcoholinduced cell growth (Fig. 6C). This indicates that Tam represses expression of Brf1 and Pol III genes, resulting in alteration of alcohol-promoted phenotypes of ER+ breast cancer cells.

\section{DISCUSSION}

In this study, we perform a mechanistic analysis characterizing that Tam represses alcohol-caused induction of Brfl and Pol III genes in ER+ breast cancer cells, resulting in decreasing the rate of cell proliferation and colony formation. Further analysis indicates that Tam

A

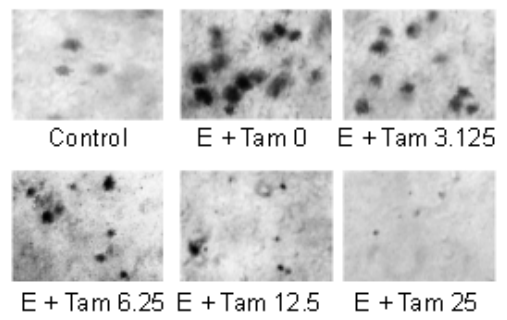

B

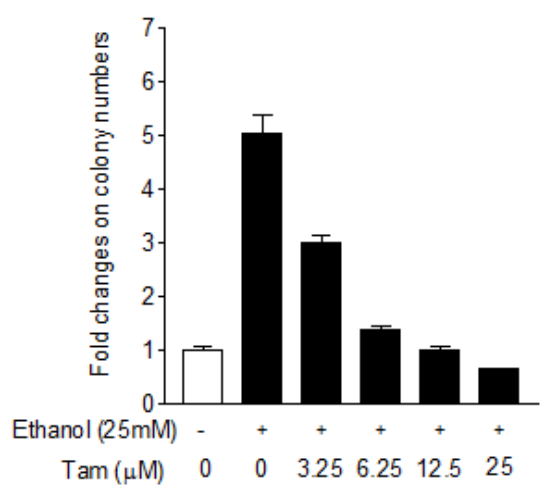

C

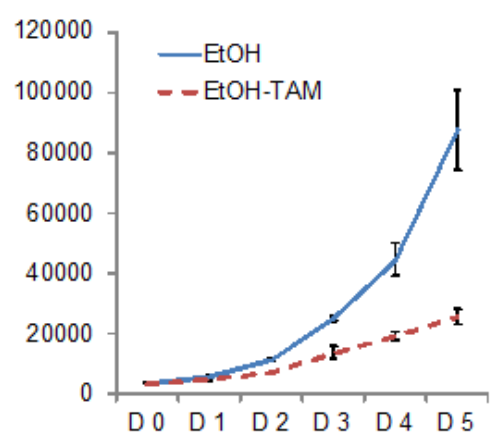

Fig.6: Tam caused phenotypic alteration induced by alcohol. (A and B) colony formation MCF-7 cells were poured in triplicate into 6 -well plate with $0.35 \%$ agar containing Tam and grown in the medium with different amounts of Tam or/and $25 \mathrm{mM}$ ethanol. The cells were analyzed for colony formation in soft agar. (C). cell proliferation MCF-7 cells were poured into 6-well plate and cultured with $12.5 \mu \mathrm{M}$ Tam or/and $25 \mathrm{mM}$ ethanol. The viability and total cell numbers were measured daily for 5 days as described before [25]. decreases c-Jun expression and lowers alcohol-increased transcription of Pol III genes, which is correlated with ER $\alpha$ expression. The ability of Tam repressing Pol III gene transcription may have important implications for the development of Pol III gene lowering medications by using possible inhibitors of c-Jun or Brf1 to improve the efficacy of Tam treatment of breast cancer.

Epidemiologic studies have demonstrated that alcohol consumption has consistently been associated with an increased risk for breast cancer in both premenopausal and postmenopausal women [12-13]. Studies by Wang et al have demonstrated that alcohol increased MCP1 and CRR2 expression, which promoted mammary tumor growth in alcohol-fed mice [18]. Alcohol intake is associated with ER+ breast cancer cases more than to ER- cases [14-15,26]. A recent study indicates that alcohol increased ER $\alpha$ expression to promote breast tumor formation in mice [19]. A previous study demonstrated that alcohol down-regulated the expression of BRCA1, a potent inhibitor of $\mathrm{ER} \alpha$, thereby contributing to breast cancer [26]. Alcohol intake was also shown to increase the transcriptional activity of ER $\alpha$ [27], as well as level of AP-1 expression [28]. We established that alcohol treatment increased c-Jun, a subunit of AP-1, expression and enhanced occupancy of TBP, Brfl and tRNA ${ }^{\text {Leu }}$ promoters by c-Jun to elevate Pol III gene transcription in HepG2-ADH cells [21]. Studies from our and other laboratories have demonstrated that ethanol induces JNK1 activation in MCF-7 cells [22,29]. We have recently reported that alcohol activates JNK1 in MCF-7 cells to increase ER $\alpha$ expression, whereas inhibition of JNK1 represses ER $\alpha$ [22]. C-Jun is downstream target of JNK. This indicates that alcohol affects ER $\alpha$ expression through c-Jun pathway to affect Brf1 and Pol III gene transcription. The result is consistent with this study, where alcohol induced JNK1 activation to increase Pol III gene transcription in HepG2-ADH cells [21]. Our previous studies have demonstrated that JNK1 positively mediates Pol III gene transcription [30]. At the present study, the results indicate that alcohol increases cellular levels of c-Jun to upregulate Brfl expression and Pol III gene transcription in MCF-7 cells. This implies that alcohol-enhanced c-Jun in both breast and liver cells may be a common signaling pathway to mediate Pol III gene transcription.

Our studies have demonstrated that EGF increased TFIIIB subunit, such as TBP, Brf1 and Bdp1, expression and enhanced Pol III gene transcription in JB6 cells [24]. Regulation of Bdp1, but not Brf1, occurred through JNK1mediated alterations in TBP expression [30], suggesting that Brf1 and Bdp1 may be regulated independently. Alcohol induced Pol III gene transcription in vivo and in vitro, where this induction promoted tumor development in liver of NS5A transgenic mouse [21]. This indicates that deregulation of Pol III genes by alcohol promotes liver tumor development. Our recent studies have revealed 
that alcohol increases ER $\alpha$ activity which specifically modulates alcohol-induced Brf1 expression, but not TBP [22]. Studies have demonstrated that oncogenic proteins or tumor suppressors interacted with TFIIIB to enhance or repress Pol III gene transcription [4-8]. TBP interacts with the $\mathrm{N}$-terminal activation domain of $\mathrm{ER} \alpha$, where it can induce and/or stabilized an ordered structure in the N-terminal regions of $\operatorname{ER} \alpha$ [31]. This indicates that ER $\alpha$ does not affect TBP expression, while the interaction between ER $\alpha$ and TBP may mediate Pol III gene transcription. In contrast, change in cellular level of ER $\alpha$ by ethanol caused an alteration of Brf1 expression. $\mathrm{ER} \alpha$ directly occupies the Brf1 promoter to modulate its expression. This finding is consistent with our recent findings that Brf1 is overexpressed in the human tissues of breast cancer (data not shown) and a previous study using human breast cancer biopsies, in which Brfl expression in ER+ breast cancer cases is higher than in ER- cases [32]. This shows that ER $\alpha$ plays a critical important role in alcohol-induced deregulation of Pol III genes and alcoholassociated ER + breast cancer. It suggests that Tam may affect the transcription of RNA Pol III genes induced by alcohol. However, nothing is known about the effects of Tam on Pol III gene transcription. Tam is currently used for the treatment of both early and advanced ER+ breast cancer in women [1]. Tam causes cells to remain in the $G_{0}$ and $G_{1}$ phases of the cell cycle to repress cell proliferation. Studies have indicated that Tam takes part in the regulation of gene transcription, such as c-jun and c-fos [2]. Given that Tam is an antagonist of the estrogen receptor in breast tissue and competitively binds to ER, we explore the role of Tam in alcohol-induced Pol III gene transcription. Our results indicate that Tam reduces cellular level of c-Jun, leading to decreases in ER $\alpha$ and Brfl to repress Pol III gene transcription. These studies increase our understandings about the role of Tam: Tam is not only competitively binds to ER to inhibit ER $\alpha$ activity, but also reduce alcohol-increased c-Jun expression to decrease ER $\alpha$ expression, resulting in repression of Brf1 and Pol III genes. The present study also suggests that Brf1 may be a novel target of Tam. The Tam-mediated alteration of Brfl expression may play an important role in alcohol-associated ER+ breast cancer.

In summary, the present study provides evidence that alcohol-induced increases in c-Jun activity enhances $\mathrm{ER} \alpha$ expression, increasing ER $\alpha$ occupancy in the Brf1 promoter to enhance Brf1 expression, resulting in elevating Pol III gene transcription. Tam reduces cellular level of c-Jun to decrease the induction of Pol III gene transcription, resulting in inhibition of alcohol-induced cell proliferation and colony formation. Our studies uncover e new mechanism of Tam-treated ER+ breast cancer cases. It may explain the efficacy of Tam treatment in ER+ breast cancer cases. This is the first report that Tam suppresses RNA Pol III-dependent transcription induced by alcohol. The novel findings suggest the possibility that inhibition of Brfl expression may be a potential approach to repress alcohol-promoted cell transformation and breast cancer development and to increase the efficacy of Tam treatment in Tam-resistant cases of ER+ breast cancer.

\section{MATERIALS AND METHODS}

\section{Cell lines, reagents and antibodies}

ER- human breast non-tumorigenic epithelial cell lines (MCF-10A, MCF-10F and MCF-10-2A), ER+ human breast cancer cell lines (MCF-7 and T-47D) and ER- human breast cancer cell lines MDA-MB231 and SKBR-3) were from ATCC (Manassas, Virginia, USA). Tamoxifen was from Sigma-Aldrich. Cell culture medium (DMEM/F12), OPTI-MEM, Lipofectamine 2000 and TRIzol reagent were from Life Technologies (San Diego, CA, USA). Antibodies against $\beta$-actin and $\mathrm{TFIIIC}_{63}$ and c-Jun siRNA (Catalog No. SC-29224) were obtained from Santa Cruz Biotech (Santa Cruz, CA, USA). Mismatch RNA was described previously [24]. Histone H3 antibody were from Cell Signaling (Danvers, MA, USA). Brf1 antibody was from Bethyl laboratories Inc (Montgomery, TX, USA). The sequences of primers were described in (Supplements) [8, 30].

\section{Real time quantitative PCR (RT-qPCR) and transfection}

The cells of human breast cancer lines and nontumor cell lines were grown to $85 \%$ confluence and starved in serum-free for $3 \mathrm{~h}$. The cells were pretreated with Tam for $1 \mathrm{~h}$ and then treated with ethanol for another $1 \mathrm{~h}$. Total RNA of these cells were extracted with TRIzol reagent (Invitrogen). For siRNA transfection assays, MCF7 cells were cultured in 10\% FBS/DMEM-F12 medium as described previously [22]. Serum-free medium was added to each dish with Lipofectamine2000-c-Jun siRNA or mismatch RNA complexes, and cells were further incubated for $4 \mathrm{~h}$ at $37 \circ \mathrm{C}$. The medium was changed with $10 \% \mathrm{FBS} / \mathrm{DMEM}-\mathrm{F} 12$ and cells were incubated for 48 $\mathrm{h}$ before harvesting. Total RNA samples were quantified and reverse-transcribed in a $20 \mu 1$ reaction containing $1 \mathrm{x}$ RT (reverse transcription) buffer. After first-strand cDNA synthesis, the cDNAs were diluted in DNase-free water and real time qPCR (RT-qPCR) were performed with specific primers (Table S1) and PCR reagent kits (BioRad Biotech) in the ABI prism 7700 Sequence Detection System. Precursor of tRNA ${ }^{\mathrm{Leu}}$ and $5 \mathrm{~S}$ rRNA transcripts and Brf1 and TFIIIC ${ }_{63}$ mRNA were measured by real time qPCR as described previously [22]. 


\section{Cell proliferation and anchorage-independent growth}

Approximately $2 \times 10^{3} \mathrm{MCF}-7$ cells were seeded in 6 well plates in triplicate. The cells were treated with 12.5 $\mu \mathrm{M}$ Tam and $25 \mathrm{mM}$ ethanol. The cells were assayed for viability and counted each day for 5 days using a Coulter Counter [25].

MCF-7 cells ( $1 \times 10^{4}$ cells/well in 6-well plate) were suspended in $0.35 \%(\mathrm{w} / \mathrm{v})$ agar in 10\% FBS/DMEM/F 12 with or without $12.5 \mu \mathrm{M}$ Tam, $25 \mathrm{mM}$ ethanol or both Tam and ethanol over a bottom layer of media with $0.5 \%(\mathrm{w} / \mathrm{v})$ agar. Cells were fed fresh complete media with Tam or/and ethanol twice weekly. Colonies were counted 2-3 weeks or longer after plating as previously described [22].

\section{Immunoblot analysis}

Cells were grown to $85 \%$ confluence in $10 \% \mathrm{FBS} /$ DMEM and then serum deprived using DMEM for $4 \mathrm{~h}$. Cells were treated with Tam for $1 \mathrm{~h}$ to extract total cell lysates. Protein concentrations of the resultant lysates were measured by the Bradford method using Fluostar Omega spectrometer (Cell Biology Core Laboratory of University of Southern California Research Center for Liver Diseases, P30 DK48522). Lysates (50 $\mu$ g of protein) were subjected to immunoblot analysis as previously described [22]. Membranes were probed with specific antibodies as indicated. Hybond-P membrane was used for protein transfer. Bound primary antibody was visualized using horseradish peroxidase-conjugated secondary antibody (Vector Laboratories) and enhanced chemiluminescence reagents (Amersham).

\section{Chromatin immunoprecipitation (ChIP) assays}

MCF-7 cells ( $3 \times 10^{6}$ cells) were cultured in $15 \mathrm{~cm}$ dishes and treated with Tam or/and ethanol. The cells were fixed with formaldehyde ( $1 \%$ final concentration) at $24^{\circ} \mathrm{C}$ for $10 \mathrm{~min}$. Soluble chromatin were prepared as described previously [25]. The chromatin were then diluted 1:10 with buffer $(0.01 \%$ SDS, $1.1 \%$ Triton X-100, $1.2 \mathrm{mM}$ EDTA, $16.7 \mathrm{mM}$ Tris- $\mathrm{HCl}$ and $167 \mathrm{mM} \mathrm{NaCl}$ ) and were subjected to immunoprecipitation (IP) in lysis buffer (50 $\mathrm{mM}$ Tris $-\mathrm{HCl}, 10 \mathrm{mM}$ EDTA, $1 \%$ SDS) and a protease inhibitor cocktail set (CalBiochem). Pre-immune serum was used as a control and antibodies of Brf1, ER $\alpha$ or histone $\mathrm{H} 3$ were used for IP. The chromatin and antibodies were incubated at $4^{\circ} \mathrm{C}$ overnight. Complex of chromatin/ antibody were recovered by adding $45 \mu \mathrm{l}$ of protein $\mathrm{A} / \mathrm{G}$ PLUS-agarose beads and incubated at $4{ }^{\circ} \mathrm{C}$ for $2 \mathrm{~h}$. The beads were sequentially washed for $10 \mathrm{~min}$ each in $1 \mathrm{ml}$ of low salt, high salt and $\mathrm{LiCl}$ immune complex wash buffer. Immunocomplexes were eluted off the beads by incubation with $200 \mu 1$ of $1 \%$ SDS and $50 \mathrm{mM} \mathrm{NaHCO}_{3}$. The eluents were incubated at $65^{\circ} \mathrm{C}$ for $6 \mathrm{~h}$ to reverse the formaldehyde-induced protein-DNA crosslinks. Extracted DNAs were resuspended in $100 \mu \mathrm{l}$ of TE and qPCR were performed for amplification [4]. The primer sequences that were used are shown in Table S2 in Supplementary Data. The fold change in promoter occupancy was calculated by setting the level of promoter occupancy in the cells without ethanol treatment at 1 .

\section{ACKNOWLEDGEMENTS}

We want to thank Dr. M. R. Stallcup (University of Southern California) for scientific discussion. This work was supported by National Institutes of Health grants AA017288, AA021114 and AA023247 to S.Z.

\section{Conflict of interest}

The authors declare no conflict of interest.

\section{REFERENCES}

1. Jordan VC. Foyrteeth Gaddum Memorial Lecture: A current view of tamoxifen for the treatment and prevention of breast cancer. Br J Pharmacol. 1993; 110: 507-517.

2. Babu RI, Naveen Kumar M, Patil RH, Devaraju KS, Ramesh GT, Sharma SC. Effect of estrogen and tamoxifen on the expression pattern of AP-1 factors in MCF-7 cells: role of c-Jun, c-Fos, and Fra-1 in cell cycle regulation. Mol. Cell. Biochem. 2013; 380:143-151.

3. White, RJ.RNA polymerase III transcription and cancer. Oncogene, 2004; 23: 3208-3216.

4. Goodfellow SJ, Innes F, Derblay LE, MacLellan WR, Scott PH, White RJ. Regulation of RNA polymerase III transcription during hypertrophic growth. EMBO J., 2006; 25: 1522-1533.

5. Zhong S, Zheng C, Johnson DL. Epidermal Growth Factor enhances cellular TBP levels and induces RNA polymerase I- and III-dependent gene activity. Mol. Cell. Biol., 2004; 24, 5119-5129.

6. Zhong S, Fromm J, Johnson DL. TBP is differentially regulated by JNK1 and JNK2 through Elk-1, controlling c-Jun expression and cell proliferation Mol. Cell. Biol., 2007; 27, 54-64.

7. Johnson SA, Johnson DL.Cell biology, RNA metabolism and oncogenesis. Science, 2008; 320, 461-462.

8. Woiwode A, Johnson SA, Zhong S, Zhang C, Roeder RG, Teichmann M, Johnson DL. PTEN represses RNA polymerase III-dependent transcription by targeting the TFIIIB complex. Mol. Cell. Biol., 2008; 28, 4204-4214.

9. Johnson SA, Dubeau L, Johnson DL. Enhanced RNA polymerase III-dependent transcription is required for oncogenic transformation. J. Biol. Chem., 2008; 283: 
19184-19191.

10. Hamajima N, Hirose K, Tajima K, Rohan T, Calle EE, Heath CW. Coates RJ, Liff JM, Chantarakul N, Koetsawang S, Rachawat D, Morabla A et al. Alcohol, tobacco and breast cancer--collaborative reanalysis of individual data from 53 epidemiological studies, including 58,515 women with breast cancer and 95,067 women without the disease. Br. J. Cancer, 2002, 87, 1234-1245,

11. MacMehon B, Epidemiology and the causes of breast cancer. Int J Cancer. 2006; 118: 2373-2378.

12. Petri AL, Tjønneland A, Gamborg M, Johansen D, Høidrup S, Sørensen TI, Grønbaek M. Alcohol intake, type of beverage, and risk of breast cancer in pre- and postmenopausal women, Alcohol Clin. Exp. Res. 2004; 28: 1084-1090.

13. Singletary KW1, Gapstur SM. Alcohol and breast cancer: review of epidemiologic and experimental evidence and potential mechanisms, JAMA., 2001; 286: 2143-2151.

14. Deandrea S, Talamini R, Foschi R, Montella M, Dal Maso L, Falcini F, La Vecchia C, Franceschi S, Negri E. Alcohol and breast cancer risk defined by estrogen and progesterone receptor status: a case-control study. Cancer Epidemiol. Biomarkers Prev., 2008; 17, 2025-2028.

15. Suzuki R, Orsini N, Mignone L, Saji S, Wolk A.Alcohol intake and risk of breast cancer defined by estrogen and progesterone receptor status--a meta-analysis of epidemiological studies. Int J Cancer. 2008; 122: 18321841.

16. Singletary KM. Nelshoppen J and Wallig M, Enhancement by chronic ethanol intake of N-methyl-Nnitrosoureainduced rat mammary tumorigenesis, Carcinogenesis 1995; 16: 959-964.

17. Singletary KW, McNary MQ, Odoms AM, Nelshoppen J, Wallig MA. Ethanol consumption and DMBA-induced mammary carcinogenesis in rats. Nutr Cancer. 1991; 16:1323.

18. Wang, S, Xu M, Li F, Wang X, Bower KA, Frank JA. Ethanol promotes mammary tumor growth and angiogenesis: the involvement of chemoattractant factor MCP-1. Breast Cancer Res Treat., 2012, 133, 1037-1048

19. Wong, A.W. Dunlap SM, Holcomb VB, Nunez NP. Alcohol Promotes Mammary Tumor Development via the Estrogen Pathway in Estrogen Receptor Alpha-Negative HER2/neu Mice. Alcohol. Clin. Exp. Res, 2012, 36, 577 587.

20. Watabiki Y, Okii T, Tokiyasu S, Yoshimura M, Yoshida A, Akane N, Shikata N, Tsubura A. Long-term ethanol consumption in ICR mice causes mammary tumor in females and liver fibrosis in males, Alcohol Clin Exp Res 2000; 24: 117S-122S.

21. Zhong S, Machida K, Tsukamoto H, Johnson DL. Alcohol induces RNA polymerase III-dependent transcription through c-jun by coregulating TBP and Brf1 expression. J Biol Chem. 2011; 286: 2393-2401.
22. Zhang Q, Jin J, Zhong Q, Yu XL, Levy D, Zhong S. ER $\alpha$ mediates alcohol-induced deregulation of Pol III genes in breast cancer cells. Carcinogenesis 2013; 34: 28-37.

23. Kushner PJ1, Agard DA, Greene GL, Scanlan TS, Shiau AK, Uht RM, Webb P. Estrogen receptor pathways to AP-1. J Steroid Biochem Mol Biol. 2000; 74(5):311-317.

24. Zhang Q, Zhong Q, Evans AG, Levy D, Zhong S. Phosphorylation of histone H3 serine 28 modulates RNA polymerase III-dependent transcription. Oncogene 2011, 30:3943-3952.

25. Zhong Q, Shi G, Zhang Q, Zhang Y, Levy D, Zhong S. Role of phosphorylated histone $\mathrm{H} 3$ serine 10 in DEN-induced deregulation of Pol III genes and cell proliferation and transformation. Carcinogenesis. 2013; 34: 2460-2469.

26. Dumitrescu, RG, Shields PG. The etiology of alcoholinduced breast cancer. Alcohol. 2005; 35, 213-225.

27. Fab, S, Meng Q, Gao B, Grossman J, Yadegari M, Goldberg ID, Rosen EM. Alcohol stimulates estrogen receptor signaling in human breast cancer cell lines. Cancer Res., 2000; 60, 5635-5639.

28. Chiu R, Boyle WJ, Meek J, Smeal T, Hunter T, Karin M. The c-fos protein interacts with c-Jun AP-1 to stimulate transcription of AP-1 responsive genes. Cell, 1998; 54, 541552.

29. Xu M, Bower KA, Wang S, Frank JA, Chen G, Ding M, Wang S, Shi X, Ke Z, Luo J. Cyanidin-3-glucoside inhibits ethanol-induced invasion of breast cancer cells overexpressing ErbB2. Mol. Cancer, 2010, 9:285

30. Zhong, S and Johnson DL. The JNKs differentially regulate RNA polymerase III transcription by coordinately modulating the expression of all TFIIIB subunits. Proc. Natl. Acad. Sci. U. S. A., 2009; 106, 12682-12687.

31. Wärnmark A1, Wikström A, Wright AP, Gustafsson JA, Härd T. The N-terminal regions of estrogen receptor alpha and beta are unstructured in vitro and show different TBP binding properties. J Biol Chem., 2001; 276, 45939-45944.

32. Julka PK, Chacko RT, Nag S, Parshad R, Nair A, Oh DS, Hu Z, Koppiker CB, Nair S, Dawar R, Dhindsa N, Miller ID, Ma D, Lin B, Awasthy B, Perou CM. A phase II study of sequential neoadjuvant gemcitabine plus doxorubicin followed by gemcitabine plus cisplatin in patients with operable breast cancer: prediction of response using molecular profiling. Br. J. Cancer. (Supplements), 2008; 98, 1327-1335. 